\title{
“O HOMEM QUE FORA CONSUMIDO” - UM CONTO DA “ALMA EXTERIOR”
}

\author{
Maria Alice Ribeiro Gabriel \\ Universidade Federal da Paraíba \\ João Pessoa, PB, BR
}

\section{Resumo}

Como ver o corpo além de sua materialidade é, obviamente, uma das maiores preocupações da ficção gótica de Edgar Allan Poe: "Metzengerstein", "Morella”, "Ligeia”, "Uma estória das montanhas Ragged", "Revelação mesmérica" e "Os fatos no caso de monsieur Valdemar" são alguns exemplos. Mas em seu grotesque cômico "O homem que fora consumido - Uma história das velhas campanhas dos Bugaboos e Kickapoos”, o humor negro e a sátira social prevalecem quando a trama centra-se no famoso brigadeiro por distinção John A. B. C. Smith e na obsessão do protagonista "Sobre este assunto - o do aspecto pessoal de Smith". Este artigo pretende estabelecer algumas observações sobre as personagens do general Smith e do narrador não nomeado, utilizando como parâmetro teórico para esta análise os conceitos de patologia da adaptação, de Mahmoud Sami-Ali, e os de personalidade narcísica e estado-limite, desenvolvidos por Didier Anzieu.

Palavras-chave: Edgar Allan Poe; estado-limite; personalidade narcísica.

\section{“THE MAN WAS USED UP” - A TALE OF THE “EXTERNAL SOUL”}

\begin{abstract}
How to see the body beyond its materiality is obviously one of majors preoccupations of Edgar Allan Poe's gothic fiction: "Metzengerstein", "Morella", "Ligeia", "A Tale of the Ragged Mountains", "Mesmeric Revelation" and "The Facts in the Case of M. Valdemar" are some examples. But in his comic grotesque "The Man Was Used Up-A Tale of the Late Bugaboo and Kickapoo Campaign", dark humour and social satire prevail when the bizarre plot focuses on the famous Brevet Brigadier General John A. B. C. Smith and the protagonist's obsession with "the topic of Smith's personal appearance". This paper intends to develop some observations on the personalities of General Smith and the unnamed narrator. The concept of pathology of adaptation, according Mahmoud SamiAli, and Didier Anzieu's structures of narcissistic personality and borderline personality disorder provide the model for this analysis.
\end{abstract}

Key words: Edgar Allan Poe; borderline personality disorder; narcissistic personality.

A violência física e psicológica é um dos temas recorrentes nos grotesques de Edgar Allan Poe, mas em "The Man Was Used Up-A Tale of the Late Bugaboo and Kickapoo Campaign", ela surge em estilo satírico. O conto atraiu a atenção dos críticos, principalmente, pela referência à agressiva política de remoção territorial que deslocou de suas terras de origem nativos americanos de variadas tribos. Tais abordagens críticas consideraram diversos aspectos do impacto das violen- tas campanhas militares contra a resistência de algumas tribos indígenas - dentre as quais, a dos Kickapoos sobre a cultura americana. "O homem que fora consumido", refere-se ao brigadeiro John A. B. C. Smith, ${ }^{1}$ herói nacional que personifica a reação do colonizador no conflito. ${ }^{2}$ J. Gerald Kennedy dedicou um estudo memorável sobre esses aspectos em "Unwinnable Wars, Unspeakable Wounds: Locating 'The Man That Was Used Up"' (2006).

\footnotetext{
" Maria Alice Ribeiro Gabriel, since 2012, has worked as a collaborating researcher with the research group Variations of Strange: from Classical Myth to Modernity of the Federal University of Paraíba (UFPB), Brazil. Her research interests include fantastic literature, psychoanalysis, and the works by Edgar Allan Poe. E-mail: rgabriel1935@gmail.com.
} 
Para Leland S. Person, em "Poe and NineteenthCentury Genders Construction" (2000), o conto apresentaria uma crítica à noção de identidade viril militar, pois revela um herói de guerra que não passa de uma "massa" corporal mutilada. Outro tema satirizado por Poe concerne à ideologia racial, presente na relação senhor/escravo entre o brigadeiro Smith e seu velho criado negro Pompey. Person também ressalta as violentas tensões implícitas nos retratos femininos caricaturais esboçados pelo narrador.

Já "Spanking the Master: Mind-Body Crossing in Poe’s Sensationalism" (2000), de David Leverenz, equaliza os narradores de "Berenice" e "O homem que fora consumido", recordando que os narradores anônimos de Poe, eventualmente, possuem sensações, mas são destituídos de sentimento; enquanto Klaus Benesch, em Romantic Cyborgs: Authorship and Technology in the American Renaissance (2002), deseja mostrar que a sátira mordaz de "O homem que fora consumido" não apenas desconstrói o proeminente papel de uma autêntica figura bélica e política, mas critica igualmente a visão da história como um fluxo contínuo, um movimento linear de avanço dirigido por eventos intrinsecamente relacionados. Para Benesch, desde o início do conto, a "espúria figura" do brigadeiro Smith é descrita mais com os atributos de uma máquina do que com atributos humanos. Assim, a artificialidade do corpo do brigadeiro Smith é exposta e referendada por Benesch como um importante aspecto da crítica metahistórica de Poe.

Segundo recorda Benesch, J. Gerald Kennedy (Poe, Death and Life of Writing, 1987) havia observado que, após 1835, devido a seu trabalho como editor, Poe estava empenhado em uma guerra pessoal envolvendo questões de plágio, e "O homem que fora consumido" poderia ser tomado como um flagrante conceito de desmembramento da noção coloquial de "using up" ou abusos de um autor ao publicar. Além disso, em um ambiente de proliferação ou multiplicação de textos, o trabalho de um escritor apareceria justo como "artificialmente" construído, a partir de fragmentos de textos de outros escritores - como o corpo e o renome histórico do brigadeiro Smith. Desse modo, a enigmática narrativa de Poe refletiria a moderna produção de textos literários.
Em uma linha de análise análoga à de Benesch, Martin Willis, em Mesmerists, Monsters, and Machines: Science Fiction and the Cultures of Science in the Nineteenth Century (2006), descreve "O homem que fora consumido" como uma amostra do interesse permanente de Poe pelo tema da contestação entre a ciência e o humano, associado ao motivo das fronteiras da realização científica, ambos em termos de seus avanços para novos estágios do conhecimento e de suas posições no panteão científico.

A crítica tem explorado o quadro cultural do século de Poe, associando dados biográficos, históricos, literários e sociológicos. Uma lacuna de entendimento cultural a respeito daquela época poderia comprometer a análise do conto, ou ainda, exacerbar os conflitos sociais abordados por Poe, descontextualizando seu autor, bem como a natureza e as causas da violência problematizada na narrativa. Considerando o impacto da violência descrita no conto sobre o corpo, a hipótese de trabalho desenvolvida neste artigo consiste em pensar as duas personalidades-chaves da história, o narrador e o brigadeiro Smith, a partir da teoria desenvolvida pelo psicanalista francês Didier Anzieu (1923-1999) sobre a personalidade narcísica e aquela denominada estado-limite.

A primeira parte do trabalho discorre sobre os elementos da narrativa e apresenta o conceito de patologia da adaptação, segundo Mahmoud Sami-Ali, que serve de prólogo à segunda parte, sobre a teoria de Didier Anzieu utilizada na análise; a terceira descreve as personalidades narcísicas e os estados-limite; a quarta avalia a personagem do brigadeiro Smith como modelo de personalidade narcísica e, a última compara o narrador ao paradigma de estado-limite. A despeito da possibilidade de incorrer em alguns erros factuais e categorias culturais forçadas, a que toda análise está sujeita, "O homem que fora consumido" mostra uma fina narrativa de eventos que delineiam, de perfis psicopatológicos a questões pontuais na história das mentalidades e da cultura americana no século XIX, oferecendo uma fonte extensiva de pesquisa e um rico acervo de informações para futuros pesquisadores de tópicos significativos na obra de Poe. 


\section{Sobre "O homem que fora consumido - Uma história das velhas campanhas dos Bugaboos e Kickapoos"}

"The Man That Was Used Up-A Tale of the Late Bugaboo and Kickapoo Campaign" foi publicado pela primeira vez em agosto de 1839, pelo Burton's Gentleman's Magazine e inserido entre os 25 contos de Tales of the Grotesque and Arabesque (1840). O conto é narrado em primeira pessoa por um homem a quem é apresentado, em circunstâncias que ele diz não recordar bem, o famoso general John A. B. C. Smith, herói da campanha militar contra as tribos indígenas dos Bugaboos e Kickapoos. O general parece, contudo, um pouco relutante em lembrar os eventos da guerra e prefere discutir as mais recentes inovações da ciência e da técnica. Decidido a saber mais sobre o passado desse homem, o narrador se dirige a diversos conhecidos e amigos para obter informações sobre as aventuras militares de John A. B. C. Smith; mas cada vez que estão referindo-se a ele, sobrevém um fato qualquer que interrompe o colóquio. No final, o narrador descobrirá a bizzarra consequência da coragem demonstrada pelo general durante a campanha contra os Bugaboos e os Kickapoos.

Os Kickapoos são uma nação indígena norte-americana que havia sido expulsa para o Texas, durante as chamadas "Guerras da Remoção" (Wars of the Removal), de 1811 a 1833 (WHITE, 1999). Para Wolfgang Martynkewicz (2005, p. 113) o termo Bugaboos refere-se ao personagem de ficção que assusta as crianças, e alude ao caráter meramente imaginário da ameaça representada pelo "homem vermelho"; para J. Gerald Kennedy (2006, p. 347), o termo alude a groudless fears (medos infundados). O personagem a que se refere o título do conto, John A. B. C. Smith, é um militar condecorado, "um perfeito desalmado, um autêntico guerreiro" (POE, s/d, p. 46), que "portou-se em combate como um herói" (POE, s/d, p. 46) e demonstrou "prodígios de bravura" (POE, s/d, p. 48) em sangrentas batalhas contra os Bugaboos e os Kickapoos.

Por fim, descobre-se que o brigadeiro segue existindo como um homem artificial (MARTYNKEWICZ, 2005, p. 113) ou ainda, um herói artificial (KENNEDY, 2006, p. 347), um ensamblaje de próteses: olhos de cristal, pernas ortopédicas, busto e ombros artificiais, próteses no lugar de braços, "uma esplêndida perna de cortiça", peruca, dentadura postiça, inclusive a língua e o palato foram substituídos. Pompey, "um velho criado negro" (POE, s/d, p. 53), compõe esse corpo (suportando impropérios e reprimendas bem distintos da elegante conversação do brigadeiro em sociedade) até adquirir aparência humana. Antes da montagem, porém, ele tem o aspecto de "uma grande trouxa de qualquer coisa, de aspecto muitíssimo estranho" (POE, s/d, p. 53).

$\mathrm{O}$ narrador, que no princípio da história ignora o verdadeiro estado do general, impressiona-se com seu aspecto imponente. "Pero el general no es más que um muñeco grotesco" (MARTYNKEWICZ, 2005, p. 113). Para Ulrike Brunotte (apud MARTYNKEWICZ, 2005, p. 113), o conto de Poe constitui uma sátira ao grotesco, pois o general admira o que o destruiu: a guerra, a moderna indústria bélica, assim como a técnica que, através das próteses, permite-lhe continuar sendo um homem: "Es tanto la víctima como el grotesco beneficiario de la técnica. Sin ella le sería materialmente imposible seguir viviendo". Poe considerava o "grotesque" (KENNEDY, 2006, p. 347) um modo menos sério, no qual a desfiguração ou o repulsivo, usualmente, assinala um propósito satírico. Algumas vezes, ele usa a deformidade para tornar um personagem perigoso ("Hop-Frog", 1849) ou aterrorizante ("The Facts in the Case of M. Valdemar", "Os fatos no caso de monsieur Valdemar", 1845). No mundo dos magazines dos dias de Poe, aplicar a expressão "used up" a alguém também era aniquilá-lo pelo criticismo. A ideia de Poe seria satirizar a autoadulação nacional que ajudava a justificar a remoção dos índios, de acordo com J. Gerald Kennedy (2006, p. 616). Mas a grande ironia do conto é a completa ausência de senso crítico das personagens em relação aos fatos: "Que história horrível!... Uma bela cáfíla de patifes, aqueles Kickapoos!... Portou-se em combate como um herói... Prodígios de bravura... Uma fama imortal. Smith!..." (POE, s/d, p. 48). Tampouco o brigadeiro Smith percebe que foi transformado em "coisa" ou sente-se "consumido" e desumanizado pela violência e ferocidade da campanha militar:

"E é que foi mesmo uma carnificina - continuou a coisa, como num solilóquio. - Mas a verdade é que 
uma pessoa não devia lutar contra os Bugaboos e os Kickapoos e julgar que se safava com uma simples beliscadura" (POE, s/d, p. 54).

A "banalidade do mal" aqui se transformou em patologia da adaptação; o corpo desfigurado, "consumido", equivale ao desaparecimento do sujeito, compensado por um sentimento de exaltação narcísica, de superioridade em relação aos outros. Para Mahmoud Sami-Ali, ${ }^{3}$ nas patologias de adaptação, pode suceder um absoluto desinteresse pelo imaginário, dentro e fora de si mesmo. O pensamento "desvia-se do imaginário para aderir ao real, um real que, aliás, não é a realidade, mas uma certa imagem da realidade tal como se encontra num contexto sociocultural particular" (SAMI-ALI, 1995, p. 76). Dessa maneira, o real corresponderia aos estereótipos de pensamento e sensibilidade, às regras de pensamento em que é perpetuada a vinculação anônima ao social, por meio do comportamento.

Norma e normalidade tornam-se intercambiáveis pelo poder que exercem dentro, poder mediatizado por uma instância interiorizada encarregada da dupla tarefa de recalcar o imaginário e substituí-lo pelo conformismo. O espaço e o tempo (em vez de serem criações emanadas do corpo, enquanto esquema de representação) são suplantados por "truques" artificiais, "quadros de referência" impostos a partir do exterior, sem o corpo, a despeito do corpo. O real acompanha-se de um "modo de usar", que concede acesso não às coisas, e sim à definição das coisas. Nessas circunstâncias,

[o] corpo transforma-se, então, em um corpo funcional cuja subjetividade é ocultada pela prótese que passou a ser. A adaptação é uma maneira de ser adotado, de encontrar no nãoser um sentimento de ser, de depender de outro para existir, diante das coisas, como corpo submetido ao espaço e ao tempo. Depender de outro que se converte num verdadeiro superego corporal o qual participa do absolutamente objetivo de uma cultura e do absolutamente subjetivo do corpo e cuja problemática é aquela, fundamental, do narcisismo formal tanto quanto material. ${ }^{4}$ (SAMI-ALI, 1995, p. 77)

Consequentemente, ainda quando é capaz de constituir "uma subjetividade sem sujeito", a adaptação em si, ou seu excesso, não estão em causa. Em compensação, o que torna a situação singular é o fato de a adaptação efetuar-se em detrimento do sujeito, permitindo-lhe ser, é verdade, ainda que seja de uma maneira impessoal em relação a outro também impessoal, e num mundo destituído de subjetividade. $\mathrm{O}$ imaginário subjetivo concede lugar a um imaginário social munido de autoridade, que o sujeito reproduz, por meio de condutas adaptativas, para portar-se comme il fault (SAMI -ALI, 1995, p. 77). A perspectiva adotada por Sami-Ali a respeito da patologia de adaptação e sua ligação com o imaginário e o narcisismo (e o aquém do narcisismo) é complementar aos estudos de Didier Anzieu, que presidem a elaboração da análise do presente estudo.

\section{Didier Anzieu e o "Eu-pele"}

Didier Anzieu (1923-1999) filia-se, sem ambiguidade, à tradição inaugurada pelo paradigma proposto por Daniel Lagache, de uma federação entre a psicanálise e a psicologia. Suas contribuições à psicologia clínica são originais, principalmente no que concerne ao domínio da nova abordagem psicanalítica das técnicas projetivas, bem como às inovações importantes que ele introduziu anteriormente no campo propriamente dito da teoria e da clínica psicanalítica, com as noções de "Eu-pele" e de "pensar". Anzieu preocupa-se em situar suas próprias concepções em relação a pontos de vista filosóficos antecedentes aos que reportam a Lacan. Para Anzieu, a perspectiva estruturalista própria a Lacan identifica-se com a corrente do racionalismo cartesiano.

Com um "esprit différent", o paradigma lagachiano ao qual Anzieu reporta-se prolonga a tradição do empirismo e do geneticismo, mais correntes na França que no mundo anglo-saxão, incluindo autores como Blaise Pascal, Étienne Bonnot de Condillac e os ideólogos do período napoleônico. Anzieu aprecia, particularmente, a obra de Pascal, citando sempre a "reversão constante do pró ao contra", a representação de um pensamento de conflito, bem mais rara na tradição francesa que na constelação germânica. Concernente aos predecessores de sua visão no campo psicanalítico, Anzieu evoca Sigmund Freud e Paul Federn, mencionando, ainda, a posteridade fecunda do pensamento de Melaine Klein, 
Donald Woods Winnicott, Wilfred Bion, Esther Bick e John Bolwby. Mas, singularmente, Anzieu jamais menciona Henri Wallon, apesar da contribuição original deste, relativa ao envelope corporal e, em geral, à psicogênese dos limites entre o interno (le dedans) e o externo (le dehors) (SAMACHER, 2005, p. 25).

Em 1974, Anzieu publicaria, pela Nouvelle Revue de Psychanalyse, um artigo de impacto determinante, intitulado "Le Moi-peau". Em 1985, apareceria, sob este mesmo título, um livro em que o autor apresentaria a síntese de suas pesquisas e a proposta de uma teoria sobre as funções do Eu-pele. A pele é o envelope do corpo, tanto como o eu tende a "envelopper", conter o aparelho psíquico. Sob este ponto de vista, as estruturas e funções da pele poderiam fornecer aos psicanalistas e aos psicólogos fecundas analogias para lhes guiar em suas reflexões e suas técnicas. O Eu-pele surgiria como um conceito operatório, explicando a sustentação do Eu sobre a pele e compreendendo uma analogia entre as funções do Eu e aquelas de nosso envelope corporal (limitar, conter, organizar). Considerar que o $\mathrm{Eu}$, como a pele, estrutura-se sobre uma interface, permite, em uma perspectiva psicanalítica, o enriquecimento das noções de fronteiras, de limites e de invólucros. Ademais, a riqueza conceitual do Eu-pele faculta meios de apreensão de uma realidade clínica complexa: para além das relações entre as afecções dermatológicas e as desordens psíquicas, o autor revela que o superinvestimento ou a carência de uma das funções do Eu-pele reportam notadamente ao masoquismo perverso, ao núcleo histérico da neurose ou à distinção entre personalidades narcísicas e estados-limite. O próprio Anzieu redigiu a definição da noção de "Eu-pele" para o Dictionnaire de psychologie de Doron e Parot, em 1991:

Notion intermédiaire entre une métaphore et um concepte, élaborée em 1974 par D. Anzieu. Le moi enveloppe l'appareil psychique comme la peau enveloppe le corps. Les principales fonctions de la peau se retrouvent transposées dans le moi: interface entre le dedans et le dehors, sac contenant dês contenus, mise em correspondence dês autres organes dês sens entre eux (consensualité) sur um fond d'espace imaginaire constitué par les expériences tactiles precoces, recharge libidinale, soutien de l'excitation sexuelle, etc. Le moi-peau est constitué de deux enveloppes psychiques: l'enveloppe pare-excitation, l'enveloppe surface d'inscription. Le repérage dês failles du moi -peau et la construction de leur origine sont une part importante du travail psychanalytique sur des patients états limites et relèvent des techniques de lanalyse transitionnelle. (ANZIEU apud SAMACHER, 2005, p. 26) ${ }^{5}$

"Dando destaque à pele como dado de origem orgânica e ao mesmo tempo imaginária, como sistema de proteção de nossa individualidade assim como primeiro instrumento e lugar de troca com o outro", Anzieu (1989, p. 3) propôs um modelo, com fundamento biológico assegurado, em que a interação com o meio encontrasse seu fundamento e que respeitasse a especificidade dos fenômenos psíquicos em relação às realidades orgânicas, bem como aos fatos sociais - em síntese, um modelo apto a enriquecer a psicologia e a psicanálise em sua teoria e em sua prática. Este modelo responde a um "retraimento no campo da observação e também no campo teórico: o psicofisiologista tende a reduzir o corpo vivo ao sistema nervoso e o comportamento às atividades cerebrais" (ANZIEU, 1989, p. 3). Recentemente, essa noção foi reelaborada, segundo um percurso inédito, "du moi-peau au moi-pensant" (do Eu-pele ao Eu-pensante), em direção a um modelo psicanalítico do pensamento, ou ainda, do "penser".

\section{Personalidades narcísicas e estados-limite}

Uma dificuldade discutida pela nosologia, pela clínica e pela técnica psicanalíticas, desde os anos 60, concerne à oportunidade de diferenciar ou não os "distúrbios narcísicos da personalidade" (mais ou menos confundidos com as "neuroses de caráter") dos "estados -limite" (às vezes confundidos com as organizações pré -psicóticas). "Nos Estados Unidos, o debate foi acirrado entre Kohut (1971) e Kerberg (1975), respectivamente partidário e adversário dessa distinção", afirma Anzieu (1989, p. 140). Uma súmula de tal debate é apresentada pelo autor nos seguintes termos:

Os estados-limite estão expostos a regressões análogas aos episódios psicóticos transitórios cuja recuperação, sempre possível mas fre- 
qüentemente difícil, requer o encontro na vida e ou nas sessões psicanalíticas de um Eu auxiliar. Este último mantém um exercício normal das funções psíquicas perturbadas ou mesmo momentaneamente destruídas pelos ataques inconscientes originados das próprias partes iradas do paciente, mas que ele considera estranhas a seu Self. O sentimento da continuidade do Self é, nos estados-limite, facilmente perdido. (ANZIEU, 1989, p. 140-1)

Segundo Anzieu (1989, p. 141): “Os distúrbios narcísicos da personalidade afetam um sentimento mais evoluído, o da coesão do Self', sentimento relacionado com um desenvolvimento insuficiente do Self. Para Kerberg, o Self advém da interiorização das relações precoces de objeto. Para Kehot, ele é fruto das vicissitudes internas do narcisismo, o qual trilha uma linha de evolução apartada daquela da relação de objeto e que passa por uma estrutura particular, a das relações com "Self-objetos", em que a distinção do Self e do objeto é insuficiente. Tais relações são investidas narcisicamente (ao passo que as relações de objeto são investidas libidinalmente); elas são analisáveis devido ao reconhecimento dos dois tipos de transferência narcísica, a transferência em espelho e a transferência idealizante. Pacientes com distúrbios narcísicos são capazes de tolerar um adiamento na satisfação do desejo, de suportar a dor moral e de se identicar com o objeto, capacidades que lhes garantem um funcionamento psíquico relativamente autônomo. Embora possam perdê-las em situações de feridas narcísicas, elas são recuperáveis, sobretudo quando tais pacientes conseguem angariar a empatia alheia.

Kernberg, em contraposição, distingue uma grande variedade de estados-limite, segundo a gravidade da patologia do caráter. Os variados graus de estados-limite abrangem ainda distúrbios narcísicos associados e diversificados, indo, do narcisismo normal até a personalidade narcísica, às neuroses narcísicas de caráter e às estruturas narcísicas patológicas definidas pelo investimento libidinal de um Self patológico, por exemplo, o Self grandioso, fusão do Self ideal com o objeto ideal e com as imagens atuais do Self. Dessa maneira "[a] função do Self grandioso é defensiva contra as imagens arcaicas de uma fragmentação interna de um Self destruidor e de um objeto persecutório em jogo nas relações de objetos precoces, investidas libidinal e agressivamente" (ANZIEU, 1989, p. 141).

A perspectiva topográfica na qual se inscreve o conceito do "Eu-pele" de Anzieu contribuiria com um argumento suplementar na distinção entre as personalidades narcísicas e os estados-limite. O "Eu-pele" normal não envolve a totalidade do aparelho psíquico e possui uma dupla face, externa e interna, separadas entre si por um espaço que deixa lugar livre para um certo jogo. "Esta limitação e essa separação tendem a desaparecer nas personalidades narcísicas", observa Anzieu (1989, p. 142). O paciente sente necessidade de se bastar com seu próprio envelope psíquico, e não preservar com o outro uma pele comum, que assinala e causa uma dependência em relação ao outro. Mas ele não detém completamente os meios de sua ambição: seu Eu-pele, que começou a se estruturar, é frágil, sendo necessário reforçá-lo - o que requer duas operações.

A primeira baseia-se em abolir a separação entre as duas faces do "Eu-pele", entre as estimulações externas e a excitação interna, entre a imagem que ele fornece de si e aquela que lhe é devolvida; seu envelope consolidase, torna-se um centro e mesmo um duplo centro de interesse: para ele mesmo e para os outros e tende a envolver a totalidade do psiquismo. Assim estendido e solidificado, esse envelope lhe traz certezas, mas não possui flexibilidade, rompendo-se ante o menor ferimento narcísico. A segunda medida do paciente para reforçar o Eu-pele carece de um elemento simbólico essencial:

A outra operação visa duplicar exteriormente
este Eu-pele pessoal cimentado com uma pele
maternal simbólica, análoga à égide de Zeus
ou a esses ouropéis ofuscantes com os quais
as jovens manequins se cobrem, muitas vezes
anoréxicas, cujo esplendor as renarcisa provi-
soriamente, face a uma ameaça inconsciente
de desagregação do continente psíquico. (AN-
ZIEU, 1989, p. 142)

Na fantasia narcísica, a mãe não conserva a pele comum com a criança, ela lhe concede esta pele, e a criança a veste triunfante. Esta generosa dádiva materna (ela se despoja de sua pele para assegurar proteção e 
força à criança durante a vida) supõe uma potencialidade benéfica: $o$ infante se imagina chamado a um destino heróico ("o que pode efetivamente levá-lo a tal"). Este envelope duplo (o da criança unido ao de sua mãe) "é brilhante, ideal; ele abastece a personalidade narcísica com a ilusão da invulnerabilidade e imortalidade", define Anzieu (1989, p. 142). Por conseguinte,

[o] duplo envelope é representado no aparelho psíquico pelo fenômeno - que vou ilustrar - da "parede dupla". Na fantasia masoquista, a mãe cruel apenas finge dar sua pele à criança. É um presente envenenado, cuja intenção, maléfica, é de retomar o Eu-pele singular da criança que será colado a esta pele, arrancando-a dolorosamente do interessado para restabelecer a fantasia de uma pele comum com ele. Isto com a decorrente dependência, com o amor reencontrado à custa da independência perdida e, em contra partida aos ferimentos de ordem moral e psíquica consentidos. (ANZIEU, 1989, p. 142)

A organização do Eu-pele em parede dupla permite às personalidades narcísicas a preservação da relação continente-conteúdo; o Eu-psíquico permanece integrado ao Eu corporal. A atividade do pensamento e do trabalho psíquico criador são, dessa forma, preservadas ou possíveis.

Já nos estados-limite, o ataque não se restringe à periferia; "é a estrutura do conjunto do Eu-pele que é alterada" (ANZIEU, 1989, p. 143). As duas faces do Eu -pele perfazem uma, e esta face única é retorcida, conforme o anel descrito pelo matemático Moebius. Foi Lacan o primeiro a comparar o Eu ao anel de Moebius: daí partiriam os distúrbios da distinção entre o que vem de dentro e o que vem de fora. Para Lacan, o Eu possui normalmente esta estrutura, capaz de o perverter e alienar. Anzieu relata que, de acordo com sua experiência, a configuração em anel de Moebius é específica dos estados-limite. Uma parte do sistema percepção-consciência, situada na interface entre o mundo exterior e a realidade interna, é movida deste local e posta em posição de observadora externa, "o paciente estado-limite assiste de fora ao funcionamento de seu corpo e de seu espírito, como expectador desinteressado de sua propria vida", ressalva Anzieu (1989, p. 143). Entretanto, a parte do sistema percepção-consciência, subsistente como interface, assegura ao indivíduo adaptação suficiente à realidade para que ele não se torne psicótico, apesar do retraimento da produção fantasmática.

Com relação aos afetos que compõem o núcleo essencial da pessoa, a dificuldade de contê-los (devido ao caráter distorcido do Eu-pele) faz com que migrem do centro para a periferia, onde eles passam a ocupar cada um dos lugares deixados livres, "pela transferência para fora, de uma parte do sistema percepção-consciência e onde, inconscientes, eles se incistam e se fragmentam em pedaços de Self escondido cujo retorno brusco à consciência é temido como uma aparição de fantasmas". Daí decorre um segundo paradoxo, conforme à mesma estrutura em anel de Moebius: "o de fora se torna o de dentro, que se torna o de fora, e assim sucessivamente, o conteúdo mal contido se torna um continente, que contém mal". Enfim, o lugar central do Self, desocupado por esses afetos primários muito violentos (desamparo, temor, ódio), torna-se um lugar vazio e a angústia desse vazio interior central constitui a queixa essencial desses pacientes, salvo, pontifica Anzieu (1989, p. 143-4), "consigam preencher esse vazio com a presença imaginária de um objeto ou de um ser ideal (uma causa, um mestre, um amor-paixão impossível, uma ideologia, etc.)". Compare-se o raciocínio de Anzieu ao do narrador de "O espelho. Esboço de uma nova teoria da alma humana", conto integrante de Papéis Avulsos (1882), de Machado de Assis:

Em primeiro lugar, não há uma só alma, há duas...

- Duas?

- Nada menos de duas almas. Cada criatura humana traz duas almas consigo: uma que olha de dentro para fora, outra que olha de fora para dentro... Espantem-se à vontade, podem ficar de boca aberta, dar de ombros, tudo; não admito réplica. Se me replicarem, acabo o charuto e vou dormir. A alma exterior pode ser um espírito, um fluido, um homem, muitos homens, um objeto, uma operação. Há casos, por exemplo, em que um simples botão de camisa é a alma exterior de uma pessoa; - e assim também a polca, o voltarete, um livro, uma máquina, um par de botas, uma cavatina, um tambor, etc. Está claro que o ofício dessa segunda alma é transmitir a vida, como a primeira; as duas 
completam o homem, que é, metafisicamente falando, uma laranja. Quem perde uma das metades, perde naturalmente metade da existência; e casos há, não raros, em que a perda da alma exterior implica a da existência inteira. Shylock, por exemplo. A alma exterior daquele judeu eram os seus ducados; perdê-los equivalia a morrer. "Nunca mais verei o meu ouro, diz ele a Tubal; é um punhal que me enterras no coração." Vejam bem esta frase; a perda dos ducados, alma exterior, era a morte para ele. Agora, é preciso saber que a alma exterior não é sempre a mesma... (ASSIS, 1994, p. 2)

A descrição de Machado de Assis, da coexistência das duas almas, "uma que olha de dentro para fora, outra que olha de fora para dentro", aproxima-se da configuração em anel de Moebius, específica dos estados-limite. Ambas propõem um paradigma para a alienação e "os distúrbios da distinção entre o que vem de dentro e o que vem de fora" (ANZIEU, 1989, p. 143).

\section{A personalidade narcísica do brigadeiro por distinção John A.B.C. Smith}

Como ilustração da personalidade narcísica, Anzieu toma uma alegoria literária, "e não um caso clínico", a partir da novela de Adolfo Bioy Casares, La invención de Morel (1940). Nesta obra, o narrador registra em seu diário uma série de alterações progressivas e incapacitantes, resultado de uma doença misteriosa que $o$ atinge paulatinamente, através da pele, afetando sua percepção do ambiente e da realidade, à medida que compromente sua propriocepção. A descrição feita por Bioy Casares ajusta-se à "ideia da existência de uma dupla pele psíquica - uma pele externa e outra interna, cujas relações vão ser esclarecidas no decorrer do texto", segundo o modelo proposto por Anzieu (1989, p. 144). Em "O homem que fora consumido", apesar do tom satírico, seria possível estabelecer uma comparação entre os modelos de personalidade narcísica e de estado-limite, descritos por Anzieu, tomando como exemplos "esse indivíduo de aspecto realmente distinto que é o brigadeiro por distinção John A. B. C. Smith" (POE, s/d, p. 43) e o narrador do conto, respectivamente. O primeiro forneceria um modelo de distúrbio narcísico, segundo a definição de Anzieu: pacientes que sofrem de distúrbios narcísicos conservam um funcionamento psíquico relativamente autônomo, com as capacidades - perdidas nos momentos de feridas narcísicas, mas recuperáveis, sobretudo se o outro demonstra empatia a respeito deles - de tolerar um atraso na satisfação do desejo, de suportar a dor moral, de se identificar com o objeto. (ANZIEU, 1989 , p. 141)

Apesar das mutilações acumuladas sobre o corpo do brigadeiro Smith, um "funcionamento psíquico relativamente autônomo" foi preservado, graças ao investimento libidinal (patológico na concepção de Kernberg) em um "Self grandioso, fusão do Selfideal com o objeto ideal e com as imagens atuais do Self” (ANZIEU, 1989, p. 141). A reparação das "feridas narcísicas" do brigadeiro Smith ocorre em sociedade, pela boa impressão que ele causa. A sua recusa em recordar suas façanhas militares origina uma certa aura de mistério em torno de sua personalidade carismática, potencializando e atualizando o seu fascínio, o que retroalimenta, direta ou indiretamente, o investimento libidinal nesse "Self grandioso". Deste modo, o Self ideal do brigadeiro Smith não é uma criação só dele, mas do efeito mítico cultivado pela imaginação coletiva. A empatia inicial que o narrador demonstra pelo brigadeiro Smith é reforçada pela curiosidade e fantasias nacionalistas em torno de sua imagem apolínea:

Havia qualquer coisa de notável, por assim dizer - notável sim, embora este seja um termo demasiado brando para exprimir tudo o que quero significar - no conjunto do indivíduo em questão. Tinha cerca de um metro e oitenta de altura, e uma presença singularmente majestosa. Havia em todo ele um ar distingué que revelava uma esmerada educação e denunciava uma boa origem. (...) Mas, embora homens tão absolutamente elegantes sejam agulha em palheiro, ainda assim eu não conseguia induzir-me a crer que o algo de notduel que há pouco referi - aquele estranho ar de je ne sais quoi que havia no meu recém-conhecido - residisse totalmente na suprema excelência dos seus dotes físicos, ou sequer a ela se devesse. Talvez pudesse descortinar-se a sua razão de ser na atitude; contudo, tão-pouco em relação a isso me arrogava qualquer certeza. Havia efectivamente um formalismo, para não dizer rigidez, 
no seu porte, um grau de precisão medida e, se assim me posso exprimir, rectangular, a acompanhar cada um dos seus movimentos, que, observados num homem de menores dimensões, teria um ligeiríssimo quê de afectação, pomposidade ou constrangimento, mas que, detectados num cavalheiro da sua indubitável estatura, logo se levavam à conta de reserva, de hauteur; em suma, de um louvável sentido do que é devido à dignidade das proporções magníficas. (POE, s/d, p. 43-4)

Anzieu (1989, p. 141) adverte: “A função do Self grandioso é defensiva contra as imagens arcaicas de uma fragmentação interna de um Self destruidor". O corpo real do brigadeiro Smith, mutilado e desfigurado "naquela tremenda guerra dos pântanos lá para o Sul, com os índios Bugaboos e Kickapoos" (POE, s/d, p. 46), não equivale à nova imagem de "proporções magníficas", moldada artificialmente, tanto pela opinião pública como por próteses mecânicas, e projetada na identidade construída por sua reputação romântica de bon causeur, "homem de maior cultura geral" e "louvável modéstia" nas soirées da época (POE, s/d, p. 47). Porém, segundo o narrador, "[e]ra um homem notável - um homem extremamente notável - aliás, um dos homens mais notáveis da sua época. Também entre as senhoras era especialmente benquisto - sobretudo por virtude da sua elevada reputação de coragem" (POE, s/d, p. 46). É esta imagem que ele pretende fixar e que o defende dos fantasmas e das memórias intoleráveis de seu "Self destruidor", apesar de sua relutância em comentar o passado:

Nunca ouvi conversador mais fluente ou homem de maior cultura geral. Com louvável modéstia, coibiu-se, porém, de aflorar o tema que nessa precisa ocasião me era mais caro: refiro-me às misteriosas circunstâncias relacionadas com a guerra dos Bugaboos; por minha parte, aquilo que considero um adequado sentido da delicadeza impedia-me de abordar o assunto, conquanto, para dizer a verdade, me sentisse extremamente tentado a fazê-lo. Notei igualmente que o galhardo soldado preferia temas de natureza filosófica e se deleitava particularmente em comentar o rápido progresso das invenções mecânicas. De facto, para onde quer que eu conduzisse a conversa, tratava-se de um tópico ao qual ele invariavelmente regressava. (POE, s/d, p. 47)

Recorde-se que, para Kernberg, os estados-limite também comportam distúrbios narcísicos "que vão do narcisismo normal até a personalidade narcísica" (ANZIEU, 1989, P. 141). Portanto, não há contradição em afirmar que, no caso do brigadeiro Smith, considerado aqui uma personalidade narcísica, seria plausível a observação de Anzieu em relação aos estados-limite:

\begin{abstract}
Quanto aos afetos que constituem o núcleo existencial da pessoa, a dificuldade de os conter (devido ao caráter distorcido do Eu-pele) os faz emigrar do centro para a periferia onde eles vêm ocupar cada um dos lugares deixados livres, pela transferência para fora, de uma parte do sistema percepção-consciência e onde, inconscientes, eles se incistam e se fragmentam em pedaços de Self escondido cujo retorno brusco à consciência é temido como uma aparição de fantasmas. (ANZIEU, 1989, p. 143)
\end{abstract}

Os afetos que constituiriam o núcleo existencial da identidade do brigadeiro Smith são dolorosos demais, temidos "como uma aparição de fantasmas", para que seu pensamento possa suportá-los e, simultaneamente, impedir ou conter seu retorno à consciência. Se o brigadeiro conta com a admiração da sociedade e construiu uma reputação heroica, paradoxalmente, foi à custa de um trauma (constantemente evocado), do qual ele tenta se esquivar, desviando o tema de sua "conversa deliciosamente brilhante" (POE, s/d, p. 46) para "o rápido progresso das invenções mecânicas”.

Enquanto personalidade narcísica, o brigadeiro Smith "tem necessidade de se bastar com seu próprio envelope psíquico, e não conservar com o outro uma pele comum que marca e provoca sua dependência em relação ao outro" (ANZIEU, 1989, p. 142). Para reforçar e estruturar seu frágil Eu-pele, recorre às duas medidas descritas por Anzieu. A primeira é a supressão do espaço de separação entre as faces interna e externa do aparelho psíquico. No Eu-pele normal, este é o espaço do devaneio, da fantasia, do imaginário, do jogo, do simbólico, do universo onírico e dos recursos internos para a elaboração dos traumas. ${ }^{6} \mathrm{Na}$ personalidade nar- 
císica é abolido o espaço entre a estimulação externa e a excitação interna, "entre a imagem que ele dá de si e aquela que lhe é devolvida; seu envelope se solidifica tornando-se um centro, e mesmo um duplo centro de interesse, para ele mesmo e para os outros" (ANZIEU, 1989, p. 142).

A outra operação, que consiste em duplicar exteriormente esse Eu-pele pessoal com uma pele maternal simbólica, "análoga à égide de Zeus ou a esses ouropéis ofuscantes (...) cujo esplendor renarcisa provisoriamente, face a uma ameaça inconsciente de desagregação do continente psíquico" (ANZIEU, 1989, p. 142), ocorre a cada vez que o brigadeiro Smith apronta-se para sair de casa, e seu criado Pompey vai, pacientemente, ajustando as próteses ao seu corpo mutilado. De acordo com Anzieu,

[n]a fantasia narcísica, a mãe não conserva a pele comum com a criança, ela lhe dá, e a criança a veste triunfante; essa generosa dádiva materna (ela se despoja de sua pele para lhe assegurar proteção e força na vida) possui uma potencialidade benéfica: a criança se imagina chamada a um destino heróico (o que pode efetivamente levá-la a tal). Este envelope duplo (o seu próprio unido ao de sua mãe) é brilhante, ideal; ele abastece a personalidade narcísica com ilusão de invulnerabilidade e imortalidade. (ANZIEU, 1989, p. 142)

Sob o prisma sustentado por Anzieu, não seria demais afirmar que a crença do brigadeiro Smith em seu destino heroico, mais que o seu corpo quase cibernético, reveste-o "com ilusão de invulnerabilidade e imortalidade", "em particular no referente aos tremendos acontecimentos quorum pars magna fuit ${ }^{7}$ durante as campanhas dos Bugaboos e dos Kickapoos" (POE, s/d, p. 48).

\section{O narrador em seu estado-limite}

A "ilusão de invulnerabilidade e imortalidade" está ausente no narrador de "O homem que fora consumido". Segundo ocorre no paciente estado-limite, de acordo com o enfoque de Anzieu (1989, p. 143), uma parte de seu sistema percepção-consciência, normalmente situado na interface entre o mundo exterior e a realidade interna, é deslocada e mantida em posição de observadora externa: "o paciente estado-limite assiste de fora ao funcionamento do seu corpo e de seu espírito, como espectador desinteressado de sua própria vida”. Assim, as primeiras páginas do conto são dedicadas à descrição pormenorizada do corpo do brigadeiro Smith. Como observou Leland S. Person (2000, p. 156): “Poe’s narrator describes the usual body parts, each of which he idealizes in the manner of an infatuated lover". "Sobre este assunto - o do aspecto pessoal de Smith sinto uma espécie de melancólica satisfação em ser minucioso" (POE, s/d, p. 43). As páginas seguintes são a transcrição da investigação pessoal que o narrador empreende junto aos conhecidos. Ele canaliza toda a sua atenção para a enigmática figura do brigadeiro Smith durante a narrativa, apresentando-se, desde o início, preso a um estado de inquietação interior permanente:

\begin{abstract}
Sou por temperamento uma pessoa nervosa; trata-se, em mim, de um defeito de família, não posso evitar. A mais leve sensação de mistério - de qualquer aspecto que não consiga compreender totalmente - coloca-me imediatamente num lamentável estado de agitação. (POE, s/d, p. 43)
\end{abstract}

O trabalho de Francisco Pizarro Obaid (2011) enfoca o aspecto psicopatológico e "el problema de la nerviosidad" dos narradores de Poe, "marcados por una estructuración psíquica singular":

El problema de lo nervioso retornará en un nuevo relato. Se trata del enigma del brigadier John A. B. C. Smith, aparente prototipo de la belleza masculina, quien literalmente será "el hombre que se gastón." La progresiva transformación de su imagen producirá un efecto ominoso en su admirador, quien se verá súbitamente confrontado al develamiento del secreto que sostenía ese cuerpo que ofrecía perfección. (OBAID, 2011, p. 9)

A parte do sistema percepção-consciência que subsiste como interface nos estados-limite, segundo Anzieu (1989, p. 143), “assegura ao indivíduo uma adaptação suficiente à realidade para que ele não seja psicótico. A produção fantasmática e sua circulação no 
ambiente próximo ficam diminuídas". Em "O homem que fora consumido" não ocorrem alucinações, pesadelos ou fantasias delirantes; o narrador preserva a sua lucidez até o final e pode discernir entre fantasia e realidade, ao inverso do que ocorre em "Berenice" (1835), "Ligeia" (1838), "William-Wilson" (1839), “O coração denunciador" (1842) e "Enterro prematuro" (1844).

Com a produção fantasmática diminuída, os afetos que formam o núcleo existencial da pessoa não podem ser contidos por um Eu-pele distorcido, que fez com que uma parte do sistema percepção-consciência migrasse para o exterior. Com ela, os afetos migram, do centro para a periferia, e se incistam numa parte do sistema percepção-consciência, tornando-se inconscientes. Daí segue-se o segundo paradoxo presente nos estados-limite, obedecendo à mesma estrutura em anel de Moebius: "o de fora se torna o de dentro, que se torna o de fora, e assim sucessivamente, o conteúdo mal contido se torna um continente, que contém mal" (ANZIEU, 1989, p. 143). Portanto, o lugar central do Self, abandonado por esses afetos primários muito violentos (desamparo, terror, ódio), se torna um lugar vazio e a angústia desse vazio interior central constitui a queixa essencial desses pacientes, ao mesmo tempo que o retorno desses afetos à consciência é temido. Existe uma possibilidade de preencher esse vazio interior, voltando ao que foi enunciado por Anzieu (1989, p. 143): "com a presença imaginária de um objeto ou de um ser ideal (uma causa, um mestre, um amor-paixão impossível, uma ideologia, etc)". No conto de Poe, o problema que ocupa e absorve os pensamentos do protagonista é que o modelo de perfeição necessário para preencher o seu vazio interior decorre, nas palavras de Anzieu (1989, p. 145), de "um erro da percepção e um distúrbio da crença do narrador". Ele não está obcecado consigo mesmo, como o sombrio Roderick Usher ou outros personagens ensimesmados de Poe:

É claro que o meu nome não é Thompson; mas escusado será dizer que deixei o brigadeiro Smith com acrescido interesse pelo homem, com uma elevada opinião dos seus dotes de eloquência e um profundo sentido dos valiosos privilégios de que desfrutamos por viver nesta época dos inventos mecânicos. A minha curiosidade não tinha, porém, sido completamente satisfeita, pelo que decidi proceder a uma imediata investigação, entre os meus conhecimentos acerca da pessoa do brigadeiro por distinção, em particular no referente aos tremendos acontecimentos quorum pars magna fuit durante as campanhas dos Bugaboos e dos Kickapoos. (POE, s/d, p. 48)

Para Anzieu (2002, p. 69), “[o] conflito é a base da vida psíquica", assim como "os conflitos do eu-realidade com o eu-ideal caracterizam as neuroses narcísicas e mais generalizadamente os estados-limite". No final de "O homem que fora consumido" e de La invención de Morel, tomando de empréstimo as palavras de Anzieu (1989, p. 146), “[o] narrador acaba por compreender que essa perturbação da crença é sua". O narrador de Poe parecia ser o único a ignorar a verdade sobre o brigadeiro Smith, embora admitisse consigo mesmo: "ainda assim eu não conseguia induzir-me a crer" que o mistério, assim como a beleza daquele corpo, "residisse totalmente na suprema excelência dos seus dotes físicos, ou sequer a ela se devesse" (POE, s/d, 45).

Se na obra de Bioy Casares, por "imprudência", observa Anzieu (1989, p. 147), "mas ainda mais por uma necessidade lógica inerente à sua crença, o narrador procede a uma investigação sobre si mesmo" que o levará a expressar por escrito o seu desejo de "que alguém invente uma máquina mais aperfeiçoada (...) que terminará de suprimir toda diferença entre a percepção e a fantasia, entre a representação de origem externa e a representação de origem interna" (ANZIEU, 1989, p. 148), o narrador de Poe retorna ao ponto de partida, após empreender uma investigação que desfaz a imago idealizada. Reduzido a uma "trouxa" grotesca o "galhardo soldado" que seria a continuidade do Self do narrador, o resultado dessa busca é uma nova queda no vazio interior dos estados-limite. O retrato das pessoas que compõem o grupo social do narrador não o diferencia muito delas. Algumas cenas mostram-nos, seja na igreja, no teatro ou nos salões, com a mesma atitude de observadores ou expectadores distraídos, como a senhora, "na verdade, gentilíssima, - que muda de alma exterior cinco, seis vezes por ano" e, "cessando a estação, a alma exterior substituise por outra" (Assis, 1994, p. 2). 
Descoberto o corpo real do brigadeiro Smith, o narrador afasta-se imediatamente de sua presença, deixando implícita a necessária reflexão ao leitor: "Lá está uma monstruosidade que parece bem em harmonia com o homem que, perseguindo sua idéia, organiza uma morte coletiva e decide por sua própria conta tornar todos seus amigos solidários” (CASARES, p. 112 apud ANZIEU, 1989, p. 147). "O que não me surpreende é que a ilusão de imortalidade seja acompanhada por uma ilusão grupal", afirma Anzieu (1989, p. 147), referindo-se à invenção de Morel, mas a assertiva poderia aplicar-se, igualmente, ao destino das personagens de "O homem que fora consumido".

\section{Considerações finais}

A busca do narrador de "O homem que fora consumido" é motivada pela projeção de um desejo romântico de complementação do Eu, e por ser facilmente seduzido por ideias de heroísmo e perfeição física. Entretanto, a narrativa de Poe continuamente escolhe diálogos perturbadores entre os personagens para descrever estas questões. A metáfora do corpo "consumido" do general oferece uma ideia das potências de um Self destruidor sobre o pensamento e a resposta de uma personalidade narcísica a tais impactos - a obra de Anzieu explora estes aspectos para distinguir como se diferencia a personalidade narcísica dos estados-limite. Poe expõe imagens de violência recíproca: "sangue e pólvora", "prodígios de bravura”, "carnificina”, "Escalpar alguém é um processo grosseiro" (POE, s/d, p. 54), "engoli alguns dentes esplêndidos quando o grande Bugaboo me calcou com a coronha da espingarda" (POE, s/d, p. 54), "arrancar olhos", "cortar pelo menos sete oitavos da língua", "Uma história bárbara, aquela dos Kicka-po-o-o-os, não foi?” (POE, s/d, p. 52) e outros comentários fragmentados sobre as atrocidades envolvendo os indígenas e o corpo "que fora consumido". A postura heroica do brigadeiro Smith e seu duelo com os nativos americanos são expostos sob uma luz negativa, apesar dos louvores em sociedade. Do mesmo modo, a atitude do general para com seu velho criado negro Pompey, pela violência de seu vocabulário, contrasta com a de seu comportamento artificialmente cultivado e afável em sociedade.
De modo geral, a ficção de Poe esboçou retratos humanos através de personagens que tentaram racionalizar as próprias inquietações e falharam. No caso do brigadeiro Smith e do narrador, ambos são punidos quando suas próprias idealizações se voltam contra eles. O herói que o brigadeiro Smith construiu arruinou seu corpo. Mas sua personalidade narcísica organizou-se de forma defensiva contra as memórias de seus feitos marciais e a devastação que estes lhe causaram. Em consequência, ele não é quem acredita ser. Porém é justamente a crença em seu destino heroico que permite ao seu corpo artificial funcionar como uma pele maternal simbólica, ou "alma exterior" que o renarcisa psiquicamente. O Eu psíquico permanece integrado no Eu corporal, impedindo uma desagregação ou colapso da personalidade. Ocorreu ao brigadeiro Smith o mesmo que ao narrador de " $\mathrm{O}$ espelho": "O alferes eliminou o homem. Durante alguns dias as duas naturezas equilibraram-se; mas não tardou que a primitiva cedesse à outra; ficou-me uma parte mínima de humanidade" (ASSIS, 1994, p. 3).

O narrador é similarmente "enganado" por um distúrbio de crença, ao tomar o brigadeiro Smith pela presença imaginária do ser idealizado para preencher seu vazio interior. Por algum tempo, seu "interesse pelo herói das campanhas dos Bugaboos e Kikhapoos tinha sido imensamente espicaçado", foi sua "alma exterior" (POE, s/d, p. 46). Ao descrever o corpo do general reduzido a uma indefinível "trouxa" humana, fruto da violenta política de remoção contra os índios e, por conseguinte, seus efeitos junto ao senso comum, Poe questiona a atitude de seu narrador de, ao descobrir "a solução de tão abominável mistério" (POE, s/d, p. 53), integrar sua visão à dos demais. Quando sua ilusão pessoal se desfaz, ele passa a enxergar o general como os que já conheciam o seu enigma. Se "a ilusão grupal dilui os espíritos dos membros de um grupo em uma psique comum" (ANZIEU, 2002, p. 184), ao final, os que se inteiravam daquela terrível incógnita eram coniventes, senão parte integrante, da "coisa, de aspecto muitíssimo estranho" (POE, s/d, p. 53) em que o brigadeiro Smith foi transformado. 


\section{Notas}

1. Na opinião de Daniel Hoffman, é possível que o modelo de Poe fosse o general Winfield Scott, que havia lutado na Flórida contra os índios. Scott pertencera ao círculo de amigos de seu pai adotivo John Allan. Klaus Theweleit aponta outro possível modelo: o famoso colonizador John Smith que viajou, em 1606 de Londres à Virgínia, para converter-se, dois anos depois, em governador do primeiro assentamento inglês do novo mundo (THEWELEIT, 199, p. 207 apud MARTYNKEWICS, 2005, p. 113).

2. Historicamente, os Kickapoos resistiram, desde o final do século XVII, à influência e controle cultural do homem branco, a começar dos franceses, mas também de outras nações, com as quais possuíam uma confederação, como os Mascoutens e Meskwakis. Dentre os povos algonquinos, os Kickapoos são os mais "obstinados" em conservar as suas tradições, o que se estendia à preservação de seu território original. A partir da primeira década do século XIX, pelo Tratado de Forth Wayne, em 1809, eles perderam suas terras. Este fato assinala o fim da política jeffersoniana de assimilação e o início da política de remoção. A retirada de centenas de índios, de diversas culturas, para um território que não poderia comportá-los adequadamente, resultou em amargos conflitos entre os povos nativos das planícies do Sul e os invasores estrangeiros do Leste (IRWIN, 2008, p. 220). De acordo com Klaus Benesch (2002, p. 123), Poe referese aos episódios das Guerras Índias da Flórida (Florida Indian Wars), assunto de um artigo que ele publicou pelo Alexander's Messenger, em 18 de março de 1840, intitulado "The Railroad War".

3. O psicanalista Mahmoud Sami-Ali é professor emérito de psicologia clínica na Universidade Paris VII e diretor científico do Centre international de psychosomatique (CIPS), fundado por ele. De naturalidade egípcia, SamiAli não tem influências culturais predominantemente ocidentais, apesar de viver em França, considerandose um homem entre duas culturas.

4. Sobre o conceito de narcisismo material, ver Sami-Ali. Corps réel - corps imaginaire. Paris: Dunod, 1984, p. 123. Na concepção de Sami-Ali, o superego corporal distingue-se a um tempo do ideal do Eu em que se projeta aquilo para o qual se tende, e do superego clássico, originário do conflito edipiano. Ele guarda, porém, determinada atividade com um e outro, na medida em que representa uma aspiração tanto quanto uma exigência. Da mesma maneira, permanece próximo, devido a um enraizamento social, do "superego cultural".

5. Noção intermediária entre uma metáfora e um conceito, elaborada em 1974 por D. Anzieu. O eu envolve o aparelho psíquico como a pele envolve o corpo. As principais funções da pele encontramse transpostas no eu: interface entre o interior e o exterior, envoltório contendo os conteúdos, dispondo em correspondência os outros órgãos dos sentidos entre si (consensualidade) sobre um fundo espacial imaginário constituído pelas experiências tácteis precoces, recarga libidinal, sustentação da excitação sexual, etc. O Eu-pele é constituído por dois envelopes psíquicos: o envelope da pára-excitação e o envelope superfície de inscrição. A detecção das falhas no Eupele e da origem destas falhas são parte importante do trabalho psicanalítico com os pacientes estadoslimite e um enriquecimento das técnicas de análise transacional (ANZIEU apud SAMACHER, 2005, p. 26, tradução nossa).

6. Didier Anzieu desenvolveu esta concepção em Pensar: do Eu-pele ao Eu-pensante (1994) e Sami Ali (1987) tratou dos efeitos da supressão desse espaço reservado ao "imaginário" sobre o corpo somático em Pensar o somático - imaginário e patologia.

7. A expressão é usada pelo herói da Eneida "para indicar que os males e desgraças de Tróia o atingiram pessoalmente: Quorum pars magna fui (Aen. 2,6). Esta expressão ganhou valor proverbial sendo repetida por quem pretende indicar que certa calamidade o atingiu directamente ou apenas para dizer, ignorando o sentido que apresentam em Virgílio, que se prestou um grande contributo para uma determinada empresa" (CARDOSO, 2009, p. 351).

\section{Referências}

ANZIEU, Didier. O Eu-Pele. São Paulo: Casa do Psicólogo, 1989.

. O Pensar. Do Eu-Pele ao Eu-Pensante. São Paulo: Casa do Psicólogo, 2002.

ASSIS, Machado de. O espelho. Esboço de uma nova teoria da alma humana. In : Obra Completa. Rio de Janeiro: Nova Aguilar 1994. V. II. Disponível em: http://www.dominiopublico.gov.br/download/texto/ bv000240.pdf. Acesso em: 18/05/2015.

BENESH, Klaus Benesch. Romantic Cyborgs: Authorship and Technology in the American Renaissance. Boston: University of Massachusettz Press, 2002.

CARDOSO, Jerónimo. Obra literária: Poesia latina. Tomo II. Coimbra: Imprensa da Universidade de Coimbra, 2002.

IRWIN, Lee. Coming Down From Above: Prophecy, Resistance, and Renewal in Native American Religions. Norman: University of Oklahoma Press, 2008.

KENNEDY, J. Gerald. (Ed.). The Portable Edgar Allan Poe. New York: Penguin Books, 2006. 
LEVERENZ, David. "Spanking the Master: Mind-Body Crossing in Poe's Sensationalism". In : KENNEDY, J. Gerald. (Ed.). A Historical Guide to Edgar Allan Poe. New York: Oxford University Press, 2000, p. 95-128.

MARTYNKEWICZ, Wolfgang. Edgar Allan Poe. Madrid: Edaf, 2005.

OBAID, Francisco Pizarro. Transformaciones y nuevas figuras de lo nervioso en la construcción de los relatos de Edgar Allan Poe. Acta Literaria, $\mathrm{N}^{\circ}$ 43, II Sem. (7993), 2011. Disponível em: http://www.scielo.cl/scielo. php?pid=S0717-68482011000200006\&script $=$ sci art text. Acesso em: 16/05/2015.

PERSON, Leland S. Poe and Nineteenth-Century Gender Constructions. In : KENNEDY, J. Gerald. (Ed.). A Historical Guide to Edgar Allan Poe. New York: Oxford University Press, 2000, p. 129-166.

POE, Edgar Allan. O homem que fora consumido. In: Histórias Extraordinárias. Tradução portuguesa de J. Teixeira de Aguilar. Mem Martins: EuropaAmérica, s/d, v.1, p. 43-55.

SAMACHER, Robert. (Coord.). Psychologie clinique et psychopathologie. Rosny: Bréal, 2005.

SAMI-ALI, Mahmoud. Pensar o Somático - Imaginário e patologia. São Paulo: Casa do Psicólogo, 1995.

WHITE, Philip M. The Kickapoo Indians, Their History and Culture: An Annotated Bibliography. Westport, CT: Greenwood, 1999.

WILLIS, Martin. Mesmerists, Monsters, and Machines: Science Fiction and the Cultures of Science in the Nineteenth Century. Kent, Ohio: Kent State University Press, 2006. 